\title{
AMPARO DÁVILA: LA ESCRITURA COMO REFUGIO ANTE LO SINIESTRO
}

\author{
Cecilia Eudave \\ Universidad de Guadalajara \\ eudave850@hotmail.com
}

Recibido: 13-01-2021

Aceptado: 14-03-2021

RESUMEN

En la presente reflexión, se abordarán algunos de los recursos literarios, desde la perspectiva de la investigación y la creación, en la obra de Amparo Dávila. Primero, su actitud poética: cómo construye sus universos amparándose en los géneros no miméticos, su relación con el lenguaje y sus premisas de creación. Después, la manera de perfilar sus personajes y sus atmósferas inquietantes a través de una sutil relación con el tiempo y el espacio, siendo aquellos el sello característico de su obra. Finalmente, abordaremos el manejo de la monstruosidad y lo siniestro en sus historias como medio para representar el contexto social que habita, señalando que su escritura es un refugio y un intersticio para resistir, para evidenciar las situaciones sociales que violentaron a las mujeres de su época.

Palabras Clave: Amparo Dávila; actitud poética; atmósferas; monstruosidad; siniestro.

\section{ABSTRACT}

In the present reflection, some literary devices in the works of Amparo Dávila will be tackled here, from the perspective of research and creativity. First, her poetic attitude: the way she builds her universes by using non-mimetic genres, her relationship with language and its creative premises. Then, the way she sketches her characters and her disturbing atmospheres through a subtle relationship with time and space, being those the characteristic imprint of her work. Finally, we will deal with the use of monstrosity and the sinister in her stories as a way to depict the social context she lives in, pinpoint- 
ing that her writing is a shelter and an interspace to resist, to show the social circumstances that outraged the women of her time.

KEY-WORDS: Amparo Dávila; poetic attitude; atmospheres; monstrosity; sinister.

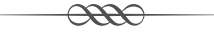

Amparo Dávila en la actualidad es considerada como una de las autoras de lo insólito más importantes del siglo xx en México y recientemente su obra se está releyendo o descubriendo en América Latina. Desde la primera vez que leí sus cuentos me percaté de que estaba ante una escritora que escogió los géneros no miméticos como herramientas para desafiar la realidad de su momento histórico, y lo logró con suma sutileza e inteligencia. Fue honesta, atrevida para su tiempo, sin apegarse a los efectismos propios de cierto tipo de literatura «realista» que asume una postura política acomodaticia o esnobista dejando de lado sus verdaderos principios intelectuales o ideológicos. Ella no se sumó a las tendencias del momento y no por ello su obra carece de compromiso. Por otra parte, es considerada por algunos como inclasificable - ella no se reconocía como una escritora fantástica en su sentido más estricto-; sin embargo, sí podemos destacar que, a pesar de que su escritura rompe con ciertas características del género, no se desliga del todo y va perfilando una modalidad distinta de lo fantástico, siendo quizá una de las primeras precursoras de lo que Carmen Alemany Bay ha denominado «narrativa de lo inusual», ${ }^{1}$ y que un número considerable de escritoras actuales están cultivando.

\section{SU ACTITUD POÉTICA Y LITERARIA}

Desde mi perspectiva, Dávila consiguió validar, no solo los géneros no miméticos en México, sino contar desde la focalización de una mujer que observa cómo el mundo la descalifica y la somete. Muchos han sido los acercamientos a su obra en las últimas dos décadas, yo misma he realizado algunas

1 «En la narrativa de lo inusual lo que prima es la incertidumbre, los hechos transcurren en un plano real — a veces en el onírico o en el delirante-, y el autor abandona al leyente en su perplejidad, pues esta ambigüedad tiende a provocar la vacilación interpretativa del lector. Por tratarse de textos muy ambiguos, el lector puede dudar de la naturaleza de esa realidad; pero insistimos, al final esta aflora con toda su contundencia» (Alemany, 2019: 313). 
lecturas y análisis de sus cuentos y, con el paso de los años, voy encontrando otros ecos, otras resonancias que a la distancia me han ayudado a leer desde distintos ángulos su escritura vigente y feroz. A disfrutar de la complicidad que intenta con el lector, a discutir con sus relatos ciertos giros argumentales que desde su singularidad solo ella podría lograr, porque narra de manera natural, sin las fijaciones retóricas a veces restrictivas y caducas. Ella no creía que el rigor estético, la técnica, o la prosa excesivamente elaborada fueran suficientes para crear:

La sola perfección formal no me interesa porque la forma no vive por sí misma, es, digamos, solo la justificación de la escritura. Hay cuentos técnicamente bien escritos pero nacen muertos, no quedan en la memoria de quien los lee. Yo no creo en la literatura hecha solo a base de inteligencia o de la pura imaginación. Creo en la literatura vivencial, ya que esto, la vivencia, es lo que comunica a la obra la clara sensación de lo conocido (...) construye su fuerza interior y su más exacta belleza (Dávila, 2009: 193).

Esa fuerza interior la consigue porque sus relatos nacen de un profundo extrañamiento vivencial y nos llevan más allá de lo formal, o de los discursos de lo terrorífico, lo fantástico, lo maravilloso, para alterar la cotidianeidad en la que se mueven sus personajes, para romper su normativa, para desestabilizar cualquier certeza a través de perspectivas inusuales que se lanzan en direcciones contrarias a lo establecido. Encuentro en su obra una poética personal con preocupaciones que privilegian la mirada femenina frente al mundo patriarcal, por una parte, y a la vez defiende y esgrime la escritura de umbrales que suele evidenciar de mejor manera los contextos que se habitan. Está consciente, como lo señalara Julio Cortázar, amigo de la escritora, que «El cuentista sabe que no puede proceder acumulativamente, que no tiene por aliado al tiempo; su único recurso es trabajar en profundidad, verticalmente» (1994: 372), con ello gana en tensión e intensidad que la mayoría de las veces la perfección formal sujeta y esclaviza.

De manera constante se señala a la figura de Cortázar como una influencia o intertexto ineludible en la obra de cualquier escritor o escritora posterior a él que escribió o escriba fantástico. Incluso sus contemporáneos, como es el caso de Dávila, no pudieron evadir esa conjetura, y si bien es cierto que en su momento el argentino instaura una manera de narrar que renueva el género, lo que se conocería después como lo neofantástico, la escritora zacatecana a pesar de las confluencias literarias o narrativas tenía otra ruta. Esta observación no pretende dilucidar si es mejor o no, pero sí enfatizar que tomó 
un camino diferente e intentó una postura afincada en la ambigüedad que le valió para construir una poética de lo insólito personal, y un universo que se ampara en la delgada línea entre la realidad, el sueño, la locura y la muerte. Además, ella reconoce que sus temáticas son limitadas, y

se reduce a mis preocupaciones fundamentales en la vida: el amor, la locura y la muerte. El amor que misteriosamente aparece un día cuándo y dónde menos se espera, y también, silenciosa y misteriosamente desaparece; la locura, ese hilo tan fino y tan sutil que separa la aparente y frágil cordura de la insania [sic] y se rompe tan fácilmente, y la muerte ese misterio tan angustioso y perturbador (2009: 193).

Es una limitación aparente porque retoma los grandes temas de nuestra condición humana y los despliega con todo el potencial que le permite su escritura orgánica, por viva, empática y honesta, sobre todo cuando habla de la situación de las mujeres de su época. A Dávila le interesa contar y que sus historias resuenen sin importar los años que le lleve redactarlas, ni los silencios que hay entre sus primeros dos libros: Tiempo destrozado (1959) y Música concreta (1961), y sus dos últimos: Árboles petrificados (1977) y Con ojos bien abiertos (2008). Porque los que escribimos reconocemos que a veces necesitamos entrar en el claustro de la escritura, mirar nuestras historias sin escribirlas, solo pensarlas, imaginarlas, creando bosquejos mentales y sobreponiéndonos al temor de qué decir y cómo decirlo desde los márgenes de lo insólito. Y tal vez, mi fascinación por Amparo Dávila, como por Elena Garro o Leonora Carrington, entre muchas otras escritoras, nace de la inspiración que produce leer su obra. Aquí me detengo para apegarme al sentido de «inspiración» que señala Roland Barthes:

Hay que dejar las imitaciones literales e inamovibles, abandonar la palabra misma y plantear que el pasaje dialéctico de la lectura amorosa a la escritura productora de una obra debe recibir otro nombre, llamaré a este pasaje Inspiración. No concibo el término en un sentido mítico romántico (la musa de Musset), ni en el sentido griego de entusiasmo, noción compleja de la que se ha ocupado Antoine Compagnon, sino el sentido inspirarse en (2005: 193).

Gracias a ese sentido de «inspirarse en», es que pasamos por todas las etapas que el semiólogo francés apunta para superar la lectura gozosa y la influencia creadora que nos provoca; y así acceder, no solo a la «esperanza» de escribir como ese otro que me fascina, sino al «deseo» de escribir desde mi propio yo encontrando mi voz escritural (2009: 193-197). 
Sirva lo anterior para resaltar la escritura única y revitalizante de Amparo Dávila en las narrativas de lo insólito en México — que por eso pervive y nos toca con su influencia-, y también como un preámbulo para acercarme a algunos elementos o recursos literarios en la obra daviliana, así como los desafíos que enfrenta en la construcción de sus cuentos desde mi lectura. Primero, hablaré sobre cómo perfila sus personajes y construye sus atmósferas; para, finalmente, centrarme en lo que me parece más sobresaliente: el manejo de la monstruosidad y lo siniestro en sus historias.

\section{LOS PERSONAJES Y SUS ATMÓSFERAS}

Los lectores de la obra daviliana reconocen que una de las mayores virtudes de sus relatos se deposita en el manejo del espacio, en la construcción de sus atmósferas. Ella misma nos orienta al respecto:

Escribo sobre seres de la vida cotidiana, insignificantes, tal vez, en su realidad, pero interesantes en su forma de existir y en su capacidad de gozo y sufrimiento, de angustia y desesperación. No enfoco mis cuentos por el lado de la estructura, sino tomando siempre al personaje como centro, su mundo particular me condiciona lo literario (2009: 193).

Si el personaje condiciona lo literario determina el espacio, ${ }^{2}$ y con ello la atmósfera sobre la cual deben prefigurar sus acciones, ellos así asientan su dominio y logran seducir al lector. Es tan poderosa la presencia de sus protagonistas que pueden provocar distintos manejos de las atmósferas y diferentes formas de asociar a sus actantes con los espacios que exigen habitar. Por ejemplo, pueden fusionarse, como en el caso del cuento «La celda»: María en el interior de su locura habita el castillo nefando, al tiempo que deambula por esa casa paterna como una prisionera y su habitación es una celda; tres instancias espaciales sofocantes y abrumadoras. También pueden alinearse argumentalmente, como se observa en «Moisés y Gaspar» que dotan los ambientes en los que se desplazan — el departamento y después la casa aislada y semiderrui-

2 «En el seno de la dimensión actuacional se sitúa el espacio del significado o de la historia, el conjunto de marcos escénicos, caracterizados mediante su vinculación con determinados personajes y acontecimientos de mayor o menor tiempo de desarrollo. Al estudiar la experiencia espacial de ficción es de justicia analizar con especial atención los diferentes ámbitos de actuación que organizan la historia, de tal modo que la trama se sustenta en los primordiales ejes espaciales de la misma. Esos grandes núcleos contienen, a su vez, múltiples subespacios y entretejen las relaciones entre los personajes, gracias a su proyección significativa» (Álvarez Méndez, 2003: 561). 
da - de oscuridad, tristeza, resignación. $\mathrm{O}$ un personaje se manifiesta como una atmósfera, como en el cuento «El huésped»; ese ser es un lugar inhabitable, es una presencia inabordable, es un clima de opresión. Dávila juega más con los espacios que con el tiempo, quizá porque sabe que este lo canibaliza, lo destroza o lo detiene. Esos personajes insignificantes, en realidad son intensos, como lo señala Luzelena Gutiérrez de Velasco Romo y en ellos subyace

ese enigma que otorga a sus cuentos una densidad que persiste más allá de la lectura. Y la insistencia en el miedo, la angustia y la desesperación de los personajes confronta los relatos con el mundo de quienes los leen. Se produce una suerte de identificación que entorpece la mirada fría, objetiva y racional sobre ese ámbito de la ficción de Dávila, porque el miedo y la angustia pueden aquejar a cualquiera (2019: 223).

Me sorprende, además, la manera en que Amparo Dávila logró despertar la identidad sofocada o rechazada de sus personajes, usando como pretexto los mundos insólitos en los que se mueven. Consigue que sus cuentos, a través de esos seres aparentemente anodinos, nos revelen el contexto mexicano de las mujeres en la primera mitad del siglo pasado, y acierte en darle una vuelta de tuerca al espacio femenino por medio de los géneros no miméticos que le permitió construir su escritura siniestra e inquietante.

\section{ESCRIBIR PARA RESISTIR LO SINIESTRO}

Lo siniestro no siempre se asocia a lo insólito, pero si lo hace potencializa su carácter polisémico. Esta mancuerna logra cubrir, con su halo múltiple y contradictorio de significación, al lector que observa y es observado por el texto. Lector franqueado por la posibilidad de mirar al otro, o por el contrario cegarse y dispensar los tormentos por los que pasa un semejante que no lo es del todo por su carácter de género. Dávila desnudó la noche eterna en la que viven las mujeres de su época, esa oscuridad que les transfiere una monstruosidad impuesta, una monstruosidad que nace de una misógina perversa, de un discurso patriarcal siniestro y descalificatorio que permite que lo masculino o masculinizado sometan a lo femenino. Así, «lo siniestro sería algo que, debiendo haber quedado oculto, se ha manifestado» (Freud, 1981: 2498) y al hacerlo «crea nuevas posibilidades de lo siniestro, que no pueden existir en la vida real» (Freud, 1981: 2504). No sería extraño que la escritora de Tiempo destrozado conociera esta lectura freudiana del indigno proceder humano, del 
aciago destino de las mujeres a manos de un pensamiento unilateral y determinativo que las volviera, no solo las malévolas eternas sino el receptáculo «eterno» de los miedos de los hombres.

La obra daviliana resiste a la testaruda inmutabilidad del contexto social que habita y busca en la escritura un refugio, un intersticio por el cual llevar un poco de luz a situaciones sociales que violentan a las mujeres. Es a través de la creación de excelentes atmósferas en sus historias que sus personajes femeninos pueden liberarse de su otro yo: el monstruoso; y los masculinos mostrar su doble mediatizado por las imposiciones discursivas patriarcales: el siniestro. Monstruos y seres maquiavélicos que producen catarsis en sus lectores y ayudan a la toma de conciencia del ser reprimido.

Esta postura escritural construyó su voz sin mirarse en el canon, sin masculinizarla, refugiándose, como lo he mencionado, en los géneros amparados por lo insólito tan periféricos, tan al margen, para denostar a la perversa sociedad mexicana de su época. Desde ahí, volvió corpóreos los temores sociales a los que se enfrentó lo femenino, principalmente, para abordar la opresión del ser humano bajo estrictos y contradictorios discursos caducos y de exclusión. Ejemplo de ello es el cuento «El huésped», donde el marido, aun sin estar presente, deja a su doble siniestro para que siga atormentando a la esposa; o en el texto «El espejo», tan perturbador, donde madre e hijo son tragados por él como una analogía de su enfermiza codependencia. Y no olvidemos el relato «El último verano», atreviéndose a hablar sobre un franco rechazo a la maternidad tardía, al alivio que produce la perdida; sin embargo, la liberación de ese peso trae consigo un autocastigo para saldar cuentas con una sociedad socavada por los preceptos morales, éticos y religiosos exacerbados.

Amparo Dávila, a su vez, evidencia los conflictos de lo masculino y nos demuestra que la «histeria» no es solo de las mujeres, como tradicionalmente se ha dicho, sino que ellos, salvaguardando su masculinidad a toda costa, se histerizan y obsesionan por perpetuar las reglas morales y su hombría aunque se llegue al feminicidio, como en los textos de «El final de una lucha» y «Música concreta», o al hostigamiento psicológico y violento tan presente en los cuentos «La celda» $\mathrm{O}$ «La señorita Julia», por mencionar algunos.

La escritora zacatecana apuesta por la ambigüedad en sus relatos, con ello desliza una doble enunciación: la pronunciada y la secreta — que subyace entre líneas-para que su discurso adquiera visibilidad de frente al México arbitrario y excluyente que le tocó vivir. Procediendo de esa forma, evidencia y refuerza el espacio íntimo propio de lo femenino como el lugar para desafiar lo altéreo. Así, la cocina, la habitación, los armarios, los espejos, los sótanos, 
los jardines, pero sobre todo el cuerpo, son los lugares para trascender y reconocer el confinamiento del que son objeto, dotándolos de halos fantásticos y revistiendo de monstruosidad a los individuos que los pueblan. Los monstruos de nuestra autora

están ahí como representaciones de otras cosas, como signo, objeto, metáfora, personificación de los deseos más ocultos, de las tendencias más oscuras. Lo terrible de la realidad se enmascara con rostros extraordinarios e infranqueables omisiones de identidad (...) Infligir y recibir dolor del otro se instaura como las únicas vías de comunicación con el mundo. La violencia entreabre espacios de comunicación que nos revelan lo insoportable de la vida cotidiana, y, al no poderlos asumir estos mutan, simbólicamente, en lugares irreales cargados de seres imposibles y ficticios. Monstruos nacidos de la imposibilidad de resistir lo vivido y lo que resta por vivir. Dávila acoge esa monstruosidad y la carga desmedidamente de violencia y caos (Eudave, 2008: 106-107).

Amparo Dávila legó a las siguientes generaciones una radiografía siniestra pero real de su contexto histórico. Abrió el camino, hizo brecha, consiguió con solo cuatro libros de cuentos que perdurara su voz, y vivió lo suficiente, desde un silencio casi fantasmal, para ver como las escritoras contemporáneas, desde este siglo xxI, reconozcamos la explosión de su literatura, de su crítica social. No intentó intelectualizar su obra, por el contrario, la dotó de cierto tipo de afectividad que le permitiera crear un yo colectivo empático donde cabían tanto mujeres como hombres intentando vencer sus roles asignados sin conseguirlo; pero asumiendo o reconociendo su confinamiento, su soledad, como un buen principio para desafiarlos. Cada vez que leo sus libros salgo fortalecida, me reconforta seguir escribiendo, seguir estudiándola y continuar esparciendo su legado desde las perspectivas de los géneros no miméticos, desde las historias que se fincan en el umbral de una realidad pactada que ya no nos alcanza para describir, o entender del todo, lo que está sucediendo en el mundo y con nuestra condición humana. Dejemos hablar a sus cuentos y sin prejuicios dialoguemos con ellos porque son espejos en los que podemos mirar la decadencia patriarcal del siglo xx.

\section{BiBLIOGRAFÍA}

Alemany Bay, Carmen (2019): «¿Una nueva modalidad de lo insólito en tiempos posmodernos? La narrativa de lo inusual», en Natalia Álvarez Méndez y Ana Abe- 
llo Verano (coord.), Realidades fracturadas. Estéticas de lo insólito en la narrativa en lengua española (1980-2018), Visor, Madrid, pp. 307-324.

Álvarez Méndez, Natalia (2003): «Hacia una teoría del signo espacial en la ficción narrativa contemporánea», Signa. Revista de la Asociación Española de Semiótica, 12, pp. 540-570.

BARTHES, Roland (2005): La preparación de la novela, Editorial Siglo XXI, Ciudad de México.

CORTÁZAR, Julio (1994): Obra crítica, vol. 2, Editorial Santillana, Madrid.

DÁvila, Amparo (2009): «Mi actitud literaria», en Regina Cardoso Nelky y Laura Cázares (eds.), Amparo Dávila. Bordar el abismo, Universidad Autónoma de México y Tecnológico de Monterrey, Campus Toluca, Ciudad de México, pp. 193.

- (2009): Cuentos reunidos, Fondo de Cultura Económica / Letras Mexicanas, Ciudad de México.

Eudave, Cecilia (2008): Sobre lo fantástico mexicano, Letra Roja Publisher, Orlando.

Freud, Sigmund (1981): Obras Completas. Tomo III, Biblioteca Nueva, Madrid.

Gutiérrez De Velasco Romo, Luzelena (2019): «La más exacta belleza en la narrativa de Amparo Dávila», en Claudia L. Gutiérrez Piña, Jazmín G. Tapia Vázquez y Rogelio Castro Rocha (coord.), Un mundo de sombras camina a mi lado. Estudios críticos de la obra de Amparo Dávila, Universidad de Guanajuato y Ediciones Académicas Colofón, Ciudad de México, pp. 222-237. 